\title{
(2) OPEN ACCESS \\ COVID-19 hospital prevalence as a risk factor for mortality: an observational study of a multistate cohort of 62 hospitals
}

\author{
Mohamad Ghazi Fakih (D) ,' Allison Ottenbacher, ${ }^{2}$ Baligh Yehia, ${ }^{1}$ \\ Richard Fogel, ${ }^{1}$ Collin Miller, ${ }^{2}$ Angela Winegar (D) , ${ }^{2}$ Christine Jesser, ${ }^{3}$ \\ Joseph Cacchione ${ }^{1}$
}

- Additional supplemental material is published online only. To view, please visit the journal online (http://dx.doi. org/10.1136/bmjgs-2021013721).

${ }^{1}$ Clinical \& Network Services, Ascension Health, Saint Louis, Missouri, USA

${ }^{2}$ Ascension Data Science Institute, Ascension Health, Saint Louis, Missouri, USA

${ }^{3}$ Ascension Clinical Research Institute, Ascension Health, Saint Louis, Missouri, USA

\section{Correspondence to} Dr Mohamad Ghazi Fakih, Clinical \& Network Services, Ascension Health, Saint Louis, MO, 63134, USA;

Mohamad.Fakih@ascension.org

Received 24 May 2021 Accepted 28 September 2021 Published Online First 5 October 2021

Check for updates

(C) Author(s) (or their employer(s)) 2022. Re-use permitted under CC BY-NC. No commercial re-use. See rights and permissions. Published by BMJ.

To cite: Fakih $M G$, Ottenbacher A, Yehia B, et al. BMJ Qual Saf 2022;31:45-53.

\begin{abstract}
Background The associated mortality with COVID-19 has improved compared with the early pandemic period. The effect of hospital COVID-19 patient prevalence on COVID-19 mortality has not been well studied.

Methods We analysed data for adults with confirmed SARS-CoV-2 infection admitted to 62 hospitals within a multistate health system over 12 months. Mortality was evaluated based on patient demographic and clinical risk factors, COVID-19 hospital prevalence and calendar time period of the admission, using a generalised linear mixed model with site of care as the random effect.

Results 38104 patients with COVID-19 were hospitalised, and during their encounters, the prevalence of COVID-19 averaged $16 \%$ of the total hospitalised population. Between March-April 2020 and JanuaryFebruary 2021, COVID-19 mortality declined from $19 \%$ to $12 \%(p<0.001)$. In the adjusted multivariable analysis, mid and high COVID-19 inpatient prevalence were associated with a $25 \%$ and $41 \%$ increase in the odds (absolute contribution to probability of death of $2 \%-3 \%$ ) of COVID-19 mortality compared with patients with COVID-19 in facilities with low prevalence $(<10 \%)$, respectively (high prevalence $>25 \%$ : adjusted OR (AOR) $1.41,95 \% \mathrm{Cl} 1.23$ to 1.61 ; mid-prevalence $(10 \%-25 \%)$ : AOR $1.25,95 \% \mathrm{Cl} 1.13$ to 1.38 ). Mid and high COVID-19 prevalence accounted for $76 \%$ of patient encounters. Conclusions Although inpatient mortality for patients with COVID-19 has sharply declined compared with earlier in the pandemic, higher COVID-19 hospital prevalence remained a common risk factor for COVID-19 mortality. Hospital leaders need to reconsider how we provide support to care for patients in times of increased volume and complexity, such as those experienced during COVID-19 surges.
\end{abstract}

In January 2020, the first case of COVID-19 was reported in the USA. ${ }^{1}$ By 25 August 2021, the USA has reported over 38.1 million confirmed cases and 631600 deaths. $^{2}$ Over the 12 months of the pandemic, we have witnessed an improvement in in-hospital COVID-19

\section{INTRODUCTION}

mortality especially compared with the initial few months. ${ }^{3}{ }^{4}$ In addition, our understanding of the clinical course and management of the disease has rapidly evolved. Some reports attributed the improvement in COVID-19 mortality partly to a change in hospitalised patient population characteristics, combined with an enhancement of medical management. ${ }^{5}$ Others focused on the relationship between COVID-19-infected patient load on the intensive care environment and the associated adverse outcomes. ${ }^{6}$

Many therapeutic and management strategies have been deployed to optimise patient outcomes with varying results. ${ }^{7-9}$ The use of dexamethasone has been associated with improved mortality, while the outcomes for other therapies were mixed. Recognising that COVID-19 can increase the risk of thrombosis, clinical guidelines recommend the use of pharmacological prophylaxis for venous thromboembolism in those hospitalised with COVID-19. ${ }^{10}$ Access to new antiviral and immune-based therapies also increased. ${ }^{11}$ In addition, the availability of COVID-19 vaccines in 2021 has provided essential protection against infection, deterioration and hospitalisation. On the other hand, the care of patients infected with COVID-19 requires substantial human, operational and clinical resources. Sudden large increases in the number of patients cared for with COVID-19 have led to increased strain on hospital capacity, especially within the critical care environment. ${ }^{612}$

To assess the impact of hospital strain on COVID-19 mortality, we evaluated changes in hospitalised patient population characteristics and hospital COVID-19 
patient prevalence over the first 12 months of the pandemic in a large multistate health system in 11 US states.

\section{METHODS}

\section{Study design, setting and population}

We conducted an observational study of a multistate health system in the USA. Adults $(\geq 18$ years old) with confirmed SARS-CoV-2 infection (positive result by PCR testing of a nasopharyngeal sample, or a COVID-19 encounter diagnosis of International Classification of Diseases, 10th Revision (ICD-10) code U07.1) admitted to 62 Ascension hospitals between 1 March 2020 and 28 February 2021 were included. Hospitals are in 11 states: Alabama $(\mathrm{n}=5)$, Florida $(n=7)$, Indiana $(n=7)$, Kansas $(n=3)$, Maryland $(n=1)$, Michigan $(n=12)$, New York $(n=2)$, Oklahoma $(n=4)$, Tennessee $(n=5)$, Texas $(n=6)$ and Wisconsin $(n=10)$. Overall, 16 (26\%) facilities had fewer than 100 beds, $22(35 \%)$ facilities had between 100 and 300 beds, and 24 (39\%) facilities had more than 300 beds. As a system, standard protocols were established early in the pandemic, regularly updated and implemented across the sites of care for COVID-19 screening, testing and management. We followed the Strengthening the Reporting of Observational Studies in Epidemiology reporting guidelines. ${ }^{13}$

\section{Data collection}

Patient sociodemographic characteristics, laboratory results and healthcare utilisation, sourced from electronic health records and administrative data, were abstracted, quality assured and assembled into a uniform database. Race was self-reported and categorised as white, black/African American or other. Patient age was standardised by subtracting the mean and dividing by the SD. Based on the date of hospital admission, patients were grouped into six consecutive 2-month time periods from March 2020 to February 2021 to evaluate trends.

The Agency for Healthcare Research and Quality (AHRQ) Elixhauser Comorbidity Index (ECI), a method of assessing comorbidities based on 29 groups of ICD-10 diagnosis codes, was calculated for each patient. ${ }^{14-16}$ The index ranged from -23 to 67 in our sample, with higher numbers indicating greater comorbidity. The ECI variable used in the model was standardised by subtracting the mean and dividing by the SD. The county-level overall Social Vulnerability Index (SVI) ${ }^{17}$ percentile rank was mapped to each encounter based on county name. However, because county was often missing in the source data, the zip code associated with the encounter was used to identify the county, which was then used to map SVI data. The categorical variable for SVI used in the model is computed based on overall percentile rank for all counties in the USA (higher percentile=higher vulnerability): low $(<0.25)$, mid-low $(0.25-<0.50)$, mid-high $(0.50-<0.75)$, high $(\geq 0.75)$.

To account for the environment where patients infected with COVID-19 may require more extensive utilisation of resources and frontline worker support, we created a variable to represent the strain on the hospital during different levels of COVID-19 hospital prevalence. The percent of inpatient hospital census that was COVID-19 positive was calculated daily for each facility by dividing the number of patients with COVID-19 by the total number of admitted patients. For each encounter, a patient-specific measure of the hospital COVID-19 prevalence was calculated by averaging (taking the mean) the daily facility per cent COVID-19 positive (referenced above) for each day between the admit date and discharge date. Each patient was assigned the corresponding categorical variable indicator for per cent COVID-19 in-hospital prevalence as follows: low $(<10 \%)$, mid $(10 \%-25 \%)$, high $(>25 \%)$. The categories for low, mid and high prevalence were assigned based on the distribution of encounters with approximately $25 \%$ of encounters experiencing low prevalence; $50 \%$ of encounters experiencing mid-prevalence and $25 \%$ of encounters experiencing high prevalence.

\section{Statistical analysis}

Statistical comparisons of patient characteristics were assessed across (1) the six 2-month time periods and (2) levels of COVID-19 hospital prevalence. Unadjusted associations between characteristics and COVID-19 hospital prevalence and time periods were evaluated using the $\mathrm{X}^{2}$ test of independence for categorical variables and Kruskal-Wallis tests for continuous variables.

A generalised linear mixed model with site of care as the random effect was used to evaluate the relationship between COVID-19 prevalence group and allcause in-hospital COVID-19 mortality. Variables that were independently associated with mortality, or identified through a literature review of previous studies that evaluated the impact of patient and clinical characteristics on COVID-19 mortality, or expert clinical recommendation, were included in the final model. Model diagnostics and fit were evaluated on the entire dataset with assessments of multicollinearity and linearity between the independent variables and the logit of the binary outcome variable. Age was considered a categorical variable for descriptive analysis but used as a continuous variable in the full model, which calculated the increased odds of mortality associated with a 1 SD increase in age (17 years). This analysis was conducted for the full sample, and separately for patients admitted to the intensive care unit (ICU). A sensitivity analysis that excluded the first 2 months of the pandemic was conducted. Two-sided testing was used and $\mathrm{p}<0.05$ was considered statistically significant. The margins package in $\mathrm{R}$ was used to calculate the average marginal effect for all independent 
variables. The average marginal effect can be interpreted as the absolute per cent difference in the probability of mortality for each level of a categorical variable relative to the reference group or a one unit change for continuous variables. All statistical analyses were performed using R V.4.0.2.

\section{RESULTS}

\section{Characteristics of patients hospitalised with COVID-19}

The final sample included 38104 patients with confirmed COVID-19, representing 7\% of all admissions during 12 months of the study, and $16 \%$ of the average census during their encounters. A total of 19270 patients (51\%) were male and 8941 (23\%) were black/African American. Median age was 67 years (IQR: 54-78); 21692 (57\%) were covered by Medicare insurance; median ECI was 9 (IQR: $0-17)$ and $8180(21 \%)$ had high social vulnerability. Common ( $>30 \%$ of patients) comorbidities included diabetes (42\%), hypertension (42\%) and obesity (35\%). On admission, $33 \%$ of patients had an oxygen saturation $<94 \%, 21 \%$ had a respiratory rate $\geq 24$ and $13 \%$ had a temperature $\geq 38^{\circ} \mathrm{C}$ (table 1 ). Overall, $24 \%$ of patient encounters occurred when there was a low COVID-19 hospital prevalence $(<10 \%), 53 \%$ of encounters occurred during times of mid-COVID-19 hospital prevalence (10\%-25\%), and 23\% occurred at times of high COVID-19 hospital prevalence (>25\%). The distribution of COVID-19 hospital prevalence changed across the 12-month period, ranging from 51\% high COVID-19 prevalence in MarchApril to 2\% high COVID-19 census in SeptemberOctober (figure 1). The number of patients infected with COVID-19 who were hospitalised during the 12 months of the study varied, with 54\% admitted between November 2020 and February 2021.

Distributions of race, age, sex, insurance, comorbidities (excluding asthma and transplant), ECI, social vulnerability, vital signs, ICU admission and hospital COVID-19 prevalence all significantly varied over this time period $(\mathrm{p}<0.05)$ (online supplemental appendix 1$)$.

\section{Outcomes of patients hospitalised with COVID-19}

Overall, 16756 (44\%) patients infected with COVID-19 were admitted to the ICU and 5009 (13\%) patients with COVID-19 died in the hospital (table 1). In-hospital COVID-19 mortality initially decreased from 19\% in March-April, to $10 \%$ in May-June, then climbed back to $14 \%$ in November-December and dropped again in January-February 2021 to $12 \%(\mathrm{p}<0.01)$. After excluding March-April, there was a significant increase in mortality between September-October and November-December $(12 \%$ to $14 \%, \mathrm{p}<0.001)$, and a significant decrease between November-December and January-February ( $14 \%$ to $12 \%, \mathrm{p}<0.001)$. The percent of patients with COVID-19 admitted to the ICU ranged from $42 \%$ to $46 \%$ during the 12 -month time frame. Mortality was highest for patients older than 85 years, ranging from 31\% in March-April to 18\% in JanuaryFebruary (figure 2).

\section{COVID-19 prevalence and in-hospital COVID-19 mortality}

Adjusting for time period, demographics, comorbidities and baseline vital signs, there were increased odds of COVID-19 mortality for patients admitted and cared for during periods of mid (adjusted OR (AOR) $1.25,95 \% \mathrm{CI} 1.13$ to 1.38 ) and high (AOR $1.41,95 \%$ CI 1.23 to 1.61$)$ COVID-19 prevalence, compared with times with low COVID-19 hospital prevalence. Higher adjusted odds of mortality for mid (AOR 1.32, 95\% CI 1.18 to 1.49) and high (AOR $1.53,95 \%$ CI 1.30 to 1.80 ) COVID-19 prevalence, compared with low, were also observed for the subset of patients who required ICU stay. After excluding the early pandemic period and examining the data in the 10 months from May 2020 to February 2021, an independent association of increased risk of mortality with higher COVID-19 prevalence remained (mid AOR 1.15, 95\% CI 1.03 to 1.29 and high AOR 1.21, 95\% CI 1.03 to 1.42 ) (online supplemental appendix 2 ). During the 10-month period, the odds of mortality remained significantly higher for ICU patients with COVID-19 in the mid-prevalence group, but was not significant for the high COVID-19 prevalence group (mid AOR 1.19, 95\% CI 1.05 to 1.36; high AOR 1.20, 95\% CI 0.99 to 1.45 ).

\section{Other factors associated with in-hospital COVID-19 mortality}

Adjusting for other factors, compared with patients admitted in March-April 2020, patients admitted in subsequent months had lower odds of COVID-19 in-hospital mortality, May-June (AOR 0.66, 95\% CI 0.55 to 0.79 ), July-August (AOR $0.67,95 \%$ CI 0.57 to 0.78 ), September-October (AOR $0.71,95 \%$ CI 0.61 to 0.84 ), November-December (AOR $0.72,95 \%$ CI 0.63 to 0.82 ), and January-February (AOR $0.58,95 \% \mathrm{CI}$ 0.51 to 0.68 ) (table 2). Older age (AOR $1.88,95 \% \mathrm{CI}$ 1.78 to 1.99 , reported race as 'other' (AOR 1.33, 95\% CI 1.16 to 1.52 ), male sex (AOR 1.27 , 95\% CI 1.19 to 1.36 ) and being a Medicare recipient (AOR $1.17,95 \%$ CI 1.05 to 1.29 ) were significantly associated with increased odds of COVID-19 mortality compared with their respective reference groups. Chronic conditions (obesity, diabetes, liver disease, ischaemic heart disease) and less favourable vital signs on admission (respiratory rate $\geq 24$ breaths/min, oxygen saturation $<94 \%$ ) were also significantly associated with increased odds of COVID-19 mortality.

Among the factors that were associated with in-hospital COVID-19 mortality, ECI contributed the highest average marginal effect $(8 \%)$ for in-hospital mortality between March 2020 and February 2021 (figure 3). Other patient characteristics that had 5\% or greater contribution include respiratory rate on 


\section{Original research}

Table 1 Characteristics of inpatients with COVID-19 admitted between March 2020 and February 2021, by COVID-19 hospital prevalence

\begin{tabular}{|c|c|c|c|c|c|}
\hline Characteristic & $\begin{array}{l}\text { Overall, } \\
\mathrm{N}=38104\end{array}$ & $\begin{array}{l}\text { Low prevalence }(<10 \%) \\
\mathrm{N}=9027\end{array}$ & $\begin{array}{l}\text { Mid prevalence } \\
(10 \%-25 \%) \mathrm{N}=20265\end{array}$ & $\begin{array}{l}\text { High prevalence }(>25 \%) \\
\mathrm{N}=8812\end{array}$ & $P$ value* \\
\hline Month admitted & & & & & $<0.001$ \\
\hline Mar-Apr & $4589(12 \%)$ & $1214(13 \%)$ & $1020(5.0 \%)$ & $2355(27 \%)$ & \\
\hline May-Jun & $2742(7.2 \%)$ & $1767(20 \%)$ & $744(3.7 \%)$ & $231(2.6 \%)$ & \\
\hline Jul-Aug & $5403(14 \%)$ & $1867(21 \%)$ & $2603(13 \%)$ & $933(11 \%)$ & \\
\hline Sep-Oct & $4733(12 \%)$ & $2394(27 \%)$ & $2242(11 \%)$ & $97(1.1 \%)$ & \\
\hline Nov-Dec & $12373(32 \%)$ & $487(5.4 \%)$ & $8559(42 \%)$ & 3327 (38\%) & \\
\hline Jan-Feb & $8264(22 \%)$ & $1298(14 \%)$ & $5097(25 \%)$ & $1869(21 \%)$ & \\
\hline Race & & & & & $<0.001$ \\
\hline White & $26692(70 \%)$ & $6074(67 \%)$ & $14624(72 \%)$ & $5994(68 \%)$ & \\
\hline Black or African American & $8941(23 \%)$ & $2187(24 \%)$ & $4451(22 \%)$ & $2303(26 \%)$ & \\
\hline Other & $2471(6.5 \%)$ & $766(8.5 \%)$ & $1190(5.9 \%)$ & $515(5.8 \%)$ & \\
\hline Age & & & & & $<0.001$ \\
\hline $18-49$ & $7167(19 \%)$ & $2067(23 \%)$ & $3659(18 \%)$ & $1441(16 \%)$ & \\
\hline $50-64$ & $9758(26 \%)$ & $2308(26 \%)$ & $5197(26 \%)$ & $2253(26 \%)$ & \\
\hline $65-84$ & $16668(44 \%)$ & $3738(41 \%)$ & 8981 (44\%) & $3949(45 \%)$ & \\
\hline $85+$ & $4511(12 \%)$ & $914(10 \%)$ & $2428(12 \%)$ & $1169(13 \%)$ & \\
\hline Age (median, IQR) & $67(54-78)$ & $65(51-76)$ & 67 (55-78) & $68(56-78)$ & $<0.001$ \\
\hline Sex & & & & & 0.002 \\
\hline Female & $18834(49 \%)$ & $4609(51 \%)$ & $9894(49 \%)$ & $4331(49 \%)$ & \\
\hline Male & $19270(51 \%)$ & $4418(49 \%)$ & $10371(51 \%)$ & $4481(51 \%)$ & \\
\hline Insurance & & & & & $<0.001$ \\
\hline Commercial & $11588(30 \%)$ & $2775(31 \%)$ & $6230(31 \%)$ & $2583(29 \%)$ & \\
\hline Medicaid & $3396(8.9 \%)$ & $1080(12 \%)$ & $1658(8.2 \%)$ & $658(7.5 \%)$ & \\
\hline Medicare & $21692(57 \%)$ & $4842(54 \%)$ & $11644(57 \%)$ & $5206(59 \%)$ & \\
\hline Other & $1428(3.7 \%)$ & $330(3.7 \%)$ & $733(3.6 \%)$ & $365(4.1 \%)$ & \\
\hline \multicolumn{6}{|l|}{ Comorbidity } \\
\hline Obesity & $13200(35 \%)$ & $3199(35 \%)$ & $6795(34 \%)$ & $3206(36 \%)$ & $<0.001$ \\
\hline Asthma & $3121(8.2 \%)$ & 799 (8.9\%) & $1627(8.0 \%)$ & $695(7.9 \%)$ & 0.030 \\
\hline $\begin{array}{l}\text { Chronic obstructive } \\
\text { pulmonary disease }\end{array}$ & $5565(15 \%)$ & $1378(15 \%)$ & $2947(15 \%)$ & $1240(14 \%)$ & 0.073 \\
\hline Diabetes & $15947(42 \%)$ & $3597(40 \%)$ & $8632(43 \%)$ & $3718(42 \%)$ & $<0.001$ \\
\hline Hypertension & $16142(42 \%)$ & $3663(41 \%)$ & $8598(42 \%)$ & $3881(44 \%)$ & $<0.001$ \\
\hline Heart failure & $6956(18 \%)$ & $1738(19 \%)$ & $3723(18 \%)$ & $1495(17 \%)$ & $<0.001$ \\
\hline $\begin{array}{l}\text { Chronic ischaemic heart } \\
\text { disease }\end{array}$ & $8462(22 \%)$ & $2018(22 \%)$ & $4541(22 \%)$ & $1903(22 \%)$ & 0.3 \\
\hline Chronic kidney disease & $8540(22 \%)$ & $1960(22 \%)$ & $4631(23 \%)$ & $1949(22 \%)$ & 0.073 \\
\hline Liver disease & $2263(5.9 \%)$ & $566(6.3 \%)$ & $1241(6.1 \%)$ & $456(5.2 \%)$ & 0.002 \\
\hline Neoplasms & $2467(6.5 \%)$ & $606(6.7 \%)$ & $1395(6.9 \%)$ & $466(5.3 \%)$ & $<0.001$ \\
\hline Transplant & $244(0.6 \%)$ & $67(0.7 \%)$ & $143(0.7 \%)$ & $34(0.4 \%)$ & 0.003 \\
\hline Elixhauser Comorbidity Index & $9(0-17)$ & $8(0-17)$ & $9(0-17)$ & $9(0-17)$ & 0.15 \\
\hline Social Vulnerability Index & & & & & $<0.001$ \\
\hline Low & $5417(14 \%)$ & $1225(13 \%)$ & $2587(13 \%)$ & $1605(18 \%)$ & \\
\hline Mid-low & $11905(31 \%)$ & $2541(28 \%)$ & $6192(31 \%)$ & $3172(36 \%)$ & \\
\hline Mid-high & $12602(33 \%)$ & $3518(39 \%)$ & $7359(36 \%)$ & $1725(20 \%)$ & \\
\hline High & $8180(21 \%)$ & $1743(19 \%)$ & $4127(20 \%)$ & $2310(26 \%)$ & \\
\hline \multicolumn{6}{|l|}{ Vital signs at admission } \\
\hline $\begin{array}{l}\text { Respiratory rate } \geq 24 \text { breaths/ } \\
\text { min }\end{array}$ & $8055(21 \%)$ & $1708(19 \%)$ & $4212(21 \%)$ & $2135(24 \%)$ & $<0.001$ \\
\hline Oxygen saturation $<94 \%$ & $12734(33 \%)$ & $2537(28 \%)$ & $6990(34 \%)$ & $3207(36 \%)$ & $<0.001$ \\
\hline Temperature $\geq 38^{\circ} \mathrm{C}$ & $5086(13 \%)$ & $1270(14 \%)$ & $2593(13 \%)$ & $1223(14 \%)$ & 0.003 \\
\hline Intensive care unit stay & $16756(44 \%)$ & $4092(45 \%)$ & 8909 (44\%) & $3755(43 \%)$ & $<0.001$ \\
\hline Mortality & $5009(13 \%)$ & $994(11 \%)$ & $2713(13 \%)$ & $1302(15 \%)$ & $<0.001$ \\
\hline
\end{tabular}

${ }^{*} \mathrm{X}^{2}$ test of independence for categorical variables and Kruskal-Wallis tests for continuous variables. 


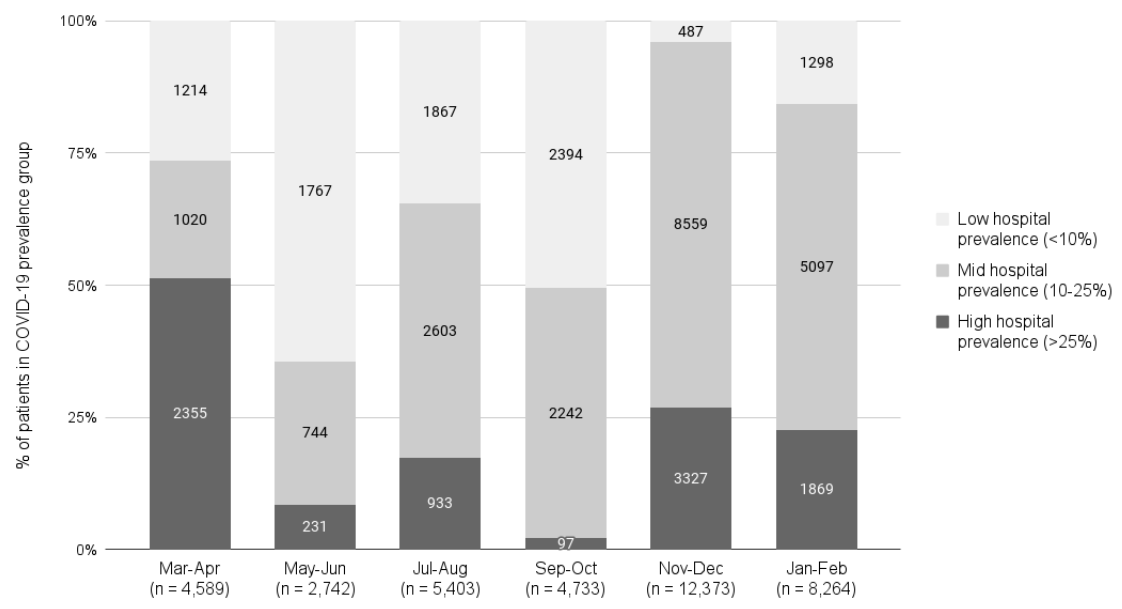

Figure 1 The number of patients and COVID-19 hospital prevalence per facility, between March 2020 and February 2021.

admission $\geq 24$ breaths/min (7\%), obesity (6\%), age $(6 \%)$, oxygen saturation on admission $<94 \%(6 \%)$ and liver disease $(5 \%)$. The average marginal effect of diabetes was $3.6 \%$ and close to the effect of high COVID-19 prevalence (3\%).

Additionally, factors found to be significant contributors of increased odds of COVID-19 mortality during the 12-month study were compared across each 2-month time period with results showing that while overall mortality decreased among patients hospitalised with COVID-19, the contribution of each risk factor to in-hospital COVID-19 mortality did not significantly differ across time periods (data not shown).

\section{DISCUSSION}

In this large multistate cohort of patients hospitalised with COVID-19 over a 12-month period, we observed an improvement in COVID-19 hospital mortality between the first 2 months of the pandemic compared with later time periods. We also identified a significant association between hospital COVID-19 prevalence during the patient stay and corresponding
COVID-19 mortality. Hospitals assumed the care for a large proportion of patients who rapidly decompensated and necessitated considerable levels of support. Adjusting for patient, clinical and hospital characteristics, the odds of dying for patients with COVID-19 infection increased between $25 \%$ and $41 \%$ when COVID-19 hospital prevalence was greater than 10\% compared with patients with COVID-19 hospital prevalence less than $10 \%$. These associations were slightly higher for patients with COVID-19 requiring intensive care support. Increased COVID-19 hospital prevalence strains health system resources via increased volumes of sicker patients who require more intense support, ${ }^{18}$ coupled with increased shortages of healthcare workers either being infected with COVID-19 1920 or quarantined due to exposure.

Hospitals experienced surge periods where rapid escalation of admissions occurred. More than threequarters of patients were cared for in periods of either mid or high hospital COVID-19 prevalence. The risk of higher mortality with increased hospital COVID-19 prevalence persisted on sensitivity analysis that excluded the first two pandemic months. Higher

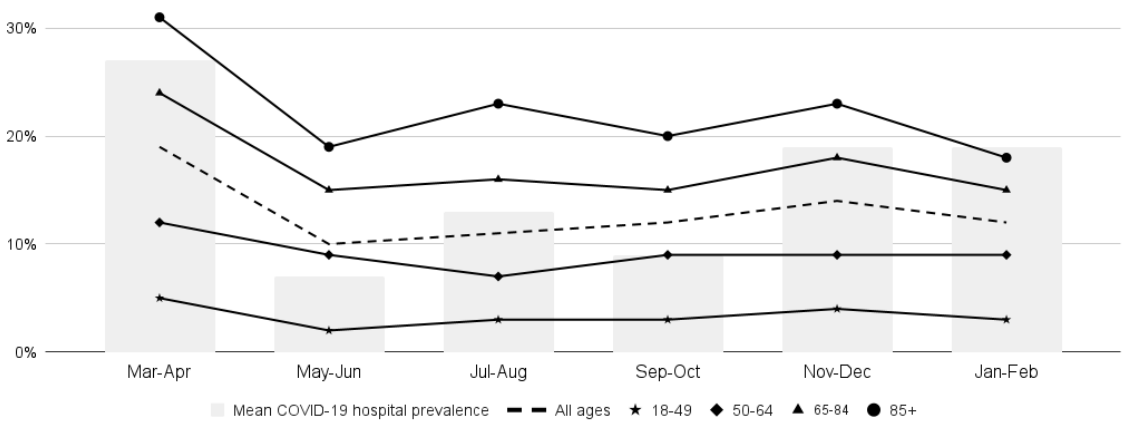

Figure 2 Mean COVID-19 hospital prevalence and mortality of inpatients infected with COVID-19 between March 2020 and February 2021 , by age. 
Table 2 Adjusted ORs (AORs) of in-hospital mortality among patients with COVID-19 admitted between March 2020 and February 2021

\begin{tabular}{|c|c|c|c|c|c|c|}
\hline \multirow[b]{2}{*}{ Characteristic } & \multicolumn{3}{|c|}{ All hospitalised patients $(\mathrm{N}=38104)$} & \multicolumn{3}{|c|}{ Patients with an ICU stay (N=16 756) } \\
\hline & AOR & $95 \% \mathrm{Cl}$ & $P$ value & AOR & $95 \% \mathrm{Cl}$ & $P$ value \\
\hline \multicolumn{7}{|l|}{ Month admitted } \\
\hline Mar-Apr & Reference & Reference & Reference & Reference & Reference & Reference \\
\hline May-Jun & 0.66 & 0.55 to 0.79 & $<0.001$ & 0.71 & 0.58 to 0.88 & 0.002 \\
\hline Jul-Aug & 0.67 & 0.57 to 0.78 & $<0.001$ & 0.78 & 0.65 to 0.94 & 0.009 \\
\hline Sep-Oct & 0.71 & 0.61 to 0.84 & $<0.001$ & 0.81 & 0.67 to 0.99 & 0.037 \\
\hline Nov-Dec & 0.72 & 0.63 to 0.82 & $<0.001$ & 0.86 & 0.73 to 1.01 & 0.067 \\
\hline Jan-Feb & 0.58 & 0.51 to 0.68 & $<0.001$ & 0.71 & 0.60 to 0.85 & $<0.001$ \\
\hline \multicolumn{7}{|l|}{ Race } \\
\hline White & Reference & Reference & Reference & Reference & Reference & Reference \\
\hline Black or African American & 0.95 & 0.86 to 1.04 & 0.3 & 1.07 & 0.96 to 1.19 & 0.2 \\
\hline Other & 1.33 & 1.16 to 1.52 & $<0.001$ & 1.36 & 1.16 to 1.60 & $<0.001$ \\
\hline Age (standardised) & 1.88 & 1.78 to 1.99 & $<0.001$ & 1.8 & 1.69 to 1.91 & $<0.001$ \\
\hline \multicolumn{7}{|l|}{ Sex } \\
\hline Female & Reference & Reference & Reference & Reference & Reference & Reference \\
\hline Male & 1.27 & 1.19 to 1.36 & $<0.001$ & 1.27 & 1.17 to 1.38 & $<0.001$ \\
\hline \multicolumn{7}{|l|}{ Insurance } \\
\hline Commercial & Reference & Reference & Reference & Reference & Reference & Reference \\
\hline Medicaid & 1.13 & 0.96 to 1.32 & 0.2 & 1.14 & 0.95 to 1.37 & 0.14 \\
\hline Medicare & 1.17 & 1.05 to 1.29 & 0.003 & 1.24 & 1.10 to 1.39 & $<0.001$ \\
\hline Other & 1.06 & 0.82 to 1.35 & 0.7 & 1.08 & 0.82 to 1.43 & 0.6 \\
\hline \multicolumn{7}{|l|}{ Comorbidity } \\
\hline Obesity & 1.92 & 1.78 to 2.08 & $<0.001$ & 1.76 & 1.60 to 1.93 & $<0.001$ \\
\hline Asthma & 0.75 & 0.65 to 0.87 & $<0.001$ & 0.63 & 0.54 to 0.74 & $<0.001$ \\
\hline Chronic obstructive pulmonary disease & 0.87 & 0.80 to 0.95 & 0.002 & 0.67 & 0.61 to 0.74 & $<0.001$ \\
\hline Diabetes & 1.47 & 1.37 to 1.58 & $<0.001$ & 1.37 & 1.26 to 1.49 & $<0.001$ \\
\hline Hypertension & 0.93 & 0.85 to 1.02 & 0.1 & 0.96 & 0.87 to 1.07 & 0.5 \\
\hline Heart failure & 0.58 & 0.52 to 0.64 & $<0.001$ & 0.58 & 0.52 to 0.65 & $<0.001$ \\
\hline Chronic ischaemic heart disease & 1.13 & 1.04 to 1.22 & 0.003 & 1.09 & 0.99 to 1.20 & 0.077 \\
\hline Chronic kidney disease & 0.87 & 0.79 to 0.95 & 0.002 & 0.97 & 0.87 to 1.08 & 0.5 \\
\hline Liver disease & 1.73 & 1.54 to 1.95 & $<0.001$ & 1.74 & 1.51 to 2.00 & $<0.001$ \\
\hline Neoplasms & 0.69 & 0.60 to 0.78 & $<0.001$ & 0.78 & 0.66 to 0.91 & 0.002 \\
\hline Transplant & 1.31 & 0.90 to 1.90 & 0.2 & 1.41 & 0.91 to 2.18 & 0.12 \\
\hline $\begin{array}{l}\text { Elixhauser comorbidity index } \\
\text { (standardised) }\end{array}$ & 2.4 & 2.30 to 2.50 & $<0.001$ & 2.06 & 1.95 to 2.17 & $<0.001$ \\
\hline \multicolumn{7}{|l|}{ Social vulnerability index } \\
\hline Low & Reference & Reference & Reference & Reference & Reference & Reference \\
\hline Mid-low & 0.97 & 0.85 to 1.11 & 0.7 & 0.93 & 0.79 to 1.09 & 0.4 \\
\hline Mid-high & 0.92 & 0.80 to 1.05 & 0.2 & 0.87 & 0.74 to 1.02 & 0.087 \\
\hline High & 1.1 & 0.96 to 1.27 & 0.2 & 1.03 & 0.87 to 1.21 & 0.8 \\
\hline \multicolumn{7}{|l|}{ Vital signs } \\
\hline Respiratory rate $\geq 24$ breaths/min & 2.17 & 2.02 to 2.34 & $<0.001$ & 1.59 & 1.46 to 1.73 & $<0.001$ \\
\hline Oxygen saturation $<94 \%$ & 1.8 & 1.68 to 1.93 & $<0.001$ & 1.55 & 1.43 to 1.68 & $<0.001$ \\
\hline Temperature $\geq 38^{\circ} \mathrm{C}$ & 1.07 & 0.97 to 1.18 & 0.2 & 1.11 & 0.99 to 1.24 & 0.068 \\
\hline \multicolumn{7}{|l|}{ COVID-19 hospital prevalence } \\
\hline $\operatorname{Low}(<10 \%)$ & Reference & Reference & Reference & Reference & Reference & Reference \\
\hline Mid $(10 \%-25 \%)$ & 1.25 & 1.13 to 1.38 & $<0.001$ & 1.32 & 1.18 to 1.49 & $<0.001$ \\
\hline High (>25\%) & 1.41 & 1.23 to 1.61 & $<0.001$ & 1.53 & 1.30 to 1.80 & $<0.001$ \\
\hline \multicolumn{7}{|l|}{ Hospital census comparison with 2019} \\
\hline Equal $(>-10 \%$ to $<10 \%)$ & Reference & Reference & Reference & Reference & Reference & Reference \\
\hline Less $(<-10 \%)$ & 0.98 & 0.86 to 1.12 & 0.8 & 0.97 & 0.83 to 1.14 & 0.7 \\
\hline More (>10\%) & 1.01 & 0.91 to 1.12 & 0.9 & 1.1 & 0.97 to 1.25 & 0.12 \\
\hline
\end{tabular}

$\mathrm{ICU}$, intensive care unit. 


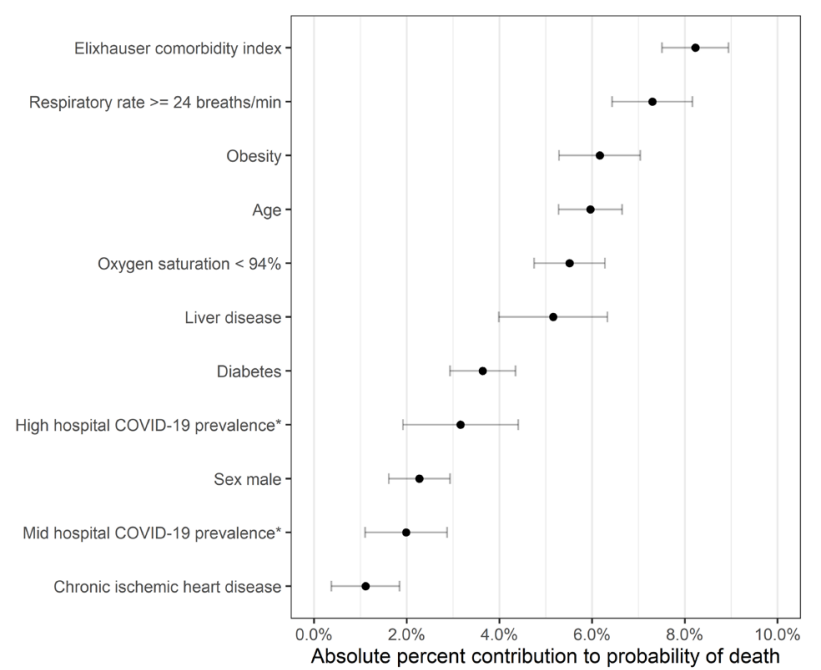

Figure 3 Characteristics with increased (absolute) per cent contribution to probability of death (average marginal effects) among patients with COVID-19. *COVID-19 prevalence compared with low COVID-19 prevalence category $(<10 \%)$.

COVID-19 hospital prevalence remained an independent risk factor for COVID-19 mortality, even as treatment knowledge improved over time. For example, the management of COVID-19 respiratory failure, treatment with steroids and antivirals, and thrombosis prophylaxis were standardised across our hospitals by May 2020. Our health system multidisciplinary team of clinical experts continues to update our clinical guidance to manage COVID-19-infected patients. The updates are regularly disseminated to clinicians and implemented locally. Acute increases in the number of inpatients infected with COVID-19 may overwhelm clinicians and disrupt standard operations, especially in high-demand areas, such as the critical care environment. ${ }^{6} 12$ ICU strain ${ }^{21}$ and bed shortages ${ }^{22}$ have been historically associated with increased mortality, but our findings show a more pronounced effect associated with COVID-19 infection. In addition, nurse staffing shortages have been perceived to adversely impact the care of patients during the pandemic. ${ }^{2324} \mathrm{~A}$ recent survey of nurses from more than 250 US hospitals reported burnout and understaffing, suggesting that the nursing workforce capacity is not prepared to withstand substantial increases in resource utilisation. ${ }^{25}$ Hospitals have attempted to mitigate shortages by recruiting travelling nurses or retraining others from different disciplines. It is uncertain that such accommodations optimally support the care of patients with COVID-19. Medical specialties, like infectious diseases and critical care medicine, heavily vested in the management of patients with COVID-19, have also been disproportionately impacted. A recent survey of more than 2000 critical care physicians revealed increased physical and emotional exhaustion, combined with staffing shortages. ${ }^{26}$ Proactive planning to adjust workforce staffing based on pandemic levels may provide more capacity and less risk for burnout. ${ }^{27}$

Some processes may have been altered during the pandemic to reduce potential exposure of frontline workers to patients. For example, the physical care of patients was often limited to essential nurses and physicians, while other clinicians performed 'electronic medical record rounding', leading to a reduction in the number of evaluations of patients per day. ${ }^{28}$ Intravenous pumps were placed in hallways in some hospitals to avoid frequent entry of nurses to rooms of patients with COVID-19. ${ }^{29}$ Process changes and increased staff workload may result in a delay in recognition of a change in patient condition. We have previously reported that hospitals with increased COVID-19 prevalence had significantly higher central line-associated bloodstream infection (CLABSI) events. ${ }^{30}$ In addition, patients infected with COVID-19 were greater than five times likely to develop CLABSIs compared with other patients during the pandemic. ${ }^{30}$ Our clinical and quality teams are re-evaluating our processes to ensure the standards of care are hardwired, patient decompensation is recognised early and prompt management is instituted for patients who are clinically deteriorating.

Our study confirms previously described associations linking intrinsic patient factors such as older age and greater comorbidity with higher in-hospital COVID-19 mortality. ${ }^{31} 32$ We observed that age, obesity, liver disease and diabetes were independently associated with increased COVID-19 mortality risk. Similar to what we have reported previously, black/African Americans did not have higher risk of COVID-19 mortality compared with white individuals over the study period. ${ }^{33}$ Another important element was the patient's clinical status at hospital presentation, where respiratory compromise was associated with twice the odds of COVID-19 mortality.

Our findings have important implications on quality of care and outcomes. First, we need to reconsider how we best support the care for patients in times of increased volume and complexity, such as those experienced during COVID-19 surges. Traditionally, clinical resources have been allocated based on the physical location of patient care (intensive care vs general medical units). The COVID-19 pandemic stressed resources even for those cared for in ICUs. ${ }^{6}$ Second, a re-evaluation of the healthcare workforce structure and its needs is essential. ${ }^{34}$ Many hospitals have limited capacity and have shown inadequate flexibility in buffering acute demands such as those seen during the pandemic. A national plan may be necessary to deploy resources-physically and virtually-and weather large disruptive events. There is a substantial opportunity to build partnerships among government, local entities and health systems. Third, the value of investing in quality and infection prevention, coupled with a robust analytics infrastructure, 
have surfaced as essential elements to identify acute changes in processes and associated adverse outcomes. Finally, national physician, nursing and specialty societies should re-examine our current state and whether we are ready to support workforce challenges in the future.

Our study has limitations. We have not specifically evaluated the therapeutic interventions that patients received during the study. We used hospital COVID-19 prevalence as a surrogate for hospital strain and healthcare workforce stress, such as staffing shortage or availability of specialty services. Results were dependent on the categorisation of COVID-19 prevalence and may vary if alternate cut-off points were specified. In addition, we have not included in the analysis the frequency of testing for patients hospitalised during the 12-month period or the potential effect of the circulating SARS-CoV-2 strain over time. Lastly, while our hospitals are located in diverse settings across multiple states, our experience may not be fully representative of other health systems in the USA or generalisable to other countries. Moreover, we have had robust system support to ensure supplies are always available to provide proper patient care. Our findings may be accentuated in other settings outside of the USA where resources may not be as available. Limitations notwithstanding, our results are based on a cohort of almost 40000 patients with COVID-19 and representative of 62 hospitals in 11 states, making our findings generalisable to the US populations.

We conclude that COVID-19 hospital prevalence is an important measure that is significantly associated with higher inpatient mortality with COVID-19 infection, independent of intrinsic patient factors. Hospital leaders should further evaluate capacity and support to address COVID-19 surges while collaborating with policymakers to support enhanced hospital preparedness to care for patients with more intense needs.

\section{Twitter Mohamad Ghazi Fakih @TheQualityDoc}

Contributors All authors have had substantial contributions to the work: MGF, JC, BY, RF and AW for the conception and design of the work; $\mathrm{AW}, \mathrm{AO}$ and $\mathrm{CM}$ for the acquisition of data; AW, AO, CM, MGF and CJ for data analysis. All authors were involved in drafting and revising the work critically for important intellectual content and have given final approval of the version to be published. MGF is responsible for the overall content as guarantor. MGF accepts full responsibility for the finished work and/or the conduct of the study, had access to the data and controlled the decision to publish.

Funding The authors have not declared a specific grant for this research from any funding agency in the public, commercial or not-for-profit sectors.

\section{Competing interests None declared.}

\section{Patient consent for publication Not required.}

Ethics approval The study was approved with a waiver of informed consent by the Ascension Seton Institutional Review Board.

Provenance and peer review Not commissioned; externally peer reviewed.
Data availability statement All data relevant to the study are included in the article or uploaded as supplemental information. Deidentified participant data are available from the Ascension Data Science Institute team.

Supplemental material This content has been supplied by the author(s). It has not been vetted by BMJ Publishing Group Limited (BMJ) and may not have been peer-reviewed. Any opinions or recommendations discussed are solely those of the author(s) and are not endorsed by BMJ. BMJ disclaims all liability and responsibility arising from any reliance placed on the content. Where the content includes any translated material, BMJ does not warrant the accuracy and reliability of the translations (including but not limited to local regulations, clinical guidelines, terminology, drug names and drug dosages), and is not responsible for any error and/or omissions arising from translation and adaptation or otherwise.

Open access This is an open access article distributed in accordance with the Creative Commons Attribution Non Commercial (CC BY-NC 4.0) license, which permits others to distribute, remix, adapt, build upon this work noncommercially, and license their derivative works on different terms, provided the original work is properly cited, appropriate credit is given, any changes made indicated, and the use is noncommercial. See: http://creativecommons.org/licenses/by-nc/4. $0 /$.

\section{ORCID iDs}

Mohamad Ghazi Fakih http://orcid.org/0000-0002-2258-8015

Angela Winegar http://orcid.org/0000-0002-3977-6506

\section{REFERENCES}

1 Holshue ML, DeBolt C, Lindquist S, et al. First case of 2019 novel coronavirus in the United States. N Engl J Med 2020;382:929-36.

2 Johns Hopkins University Center for Systems Science and Engineering. United States coronavirus (2019-nCoV) cases. Available: https:/gisanddata.maps.arcgis.com/apps/ opsdashboard/index.html\#/bda7594740fd40299423467b 48e9ecf6 [Accessed 25 Aug 2021].

3 Finelli L, Gupta V, Petigara T, et al. Mortality among US patients hospitalized with SARS-CoV-2 infection in 2020. JAMA Netw Open 2021;4:e216556.

4 Roth GA, Emmons-Bell S, Alger HM, et al. Trends in patient characteristics and COVID-19 in-hospital mortality in the United States during the COVID-19 pandemic. JAMA Netw Open 2021;4:e218828.

5 Horwitz LI, Jones SA, Cerfolio RJ, et al. Trends in COVID-19 risk-adjusted mortality rates. J Hosp Med 2021;16:90-2.

6 Bravata DM, Perkins AJ, Myers LJ, et al. Association of intensive care unit patient load and demand with mortality rates in US department of veterans affairs hospitals during the COVID-19 pandemic. JAMA Netw Open 2021;4:e2034266.

7 RECOVERY Collaborative Group, Horby P, Lim WS, et al. Dexamethasone in hospitalized patients with Covid-19. N Engl J Med 2021;384:693-704.

8 RECOVERY Collaborative Group, Horby P, Mafham M, et al. Effect of hydroxychloroquine in hospitalized patients with Covid-19. N Engl J Med 2020;383:2030-40.

9 Beigel JH, Tomashek KM, Dodd LE, et al. Remdesivir for the treatment of Covid-19 - final report. N Engl J Med 2020;383:1813-26.

10 Cuker A, Tseng EK, Nieuwlaat R, et al. American Society of hematology 2021 guidelines on the use of anticoagulation for thromboprophylaxis in patients with COVID-19. Blood Adv 2021;5:872-88.

11 National Institutes of Health. COVID-19 treatment guidelines panel. coronavirus disease 2019 (COVID-19) treatment 
guidelines. Available: https://www.covid19treatmentguidelines. nih.gov/ [Accessed 04 May 2021].

12 Dale CR, Starcher RW, Chang SC, et al. Surge effects and survival to hospital discharge in critical care patients with COVID-19 during the early pandemic: a cohort study. Crit Care 2021;25:70.

13 von Elm E, Altman DG, Egger M, et al. The strengthening the reporting of observational studies in epidemiology (strobe) statement: guidelines for reporting observational studies. The Lancet 2007;370:1453-7.

14 Elixhauser A, Steiner C, Harris DR, et al. Comorbidity measures for use with administrative data. Med Care 1998;36:8-27.

15 Gasparini A. Comorbidity: an R package for computing comorbidity scores. JOSS 2018;3:648.

16 Moore BJ, White S, Washington R, et al. Identifying increased risk of readmission and in-hospital mortality using hospital administrative data: the AHRQ elixhauser comorbidity index. Med Care 2017;55:698-705.

17 Agency for toxic substances and disease registry. CDC/ATSDR social vulnerability index (SVI). Available: https://www.atsdr. cdc.gov/placeandhealth/svi/ [Accessed 02 May 2021].

18 Bhatla A, Ryskina KL. Hospital and ICU patient volume per physician at peak of COVID pandemic: State-level estimates. Healthc 2020;8:100489.

19 Bielicki JA, Duval X, Gobat N, et al. Monitoring approaches for health-care workers during the COVID-19 pandemic. Lancet Infect Dis 2020;20:e261-7.

20 Shah ASV, Wood R, Gribben C, et al. Risk of hospital admission with coronavirus disease 2019 in healthcare workers and their households: nationwide linkage cohort study. BMJ 2020;371:m3582.

21 Gabler NB, Ratcliffe SJ, Wagner J, et al. Mortality among patients admitted to strained intensive care units. Am J Respir Crit Care Med 2013;188:800-6.

22 Madsen F, Ladelund S, Linneberg A. High levels of bed occupancy associated with increased inpatient and thirty-day hospital mortality in Denmark. Health Aff 2014;33:1236-44.

23 McGarry BE, Grabowski DC, Barnett ML. Severe staffing and personal protective equipment shortages faced by nursing homes during thstaffing and personal protective equipment shortages faced by nursing homes during the covid-19 pandemic. Health Aff 2020;39:1812-21.

24 Turale S, Meechamnan C, Kunaviktikul W. Challenging times: ethics, nursing and the COVID-19 pandemic. Int Nurs Rev 2020;67:164-7.

25 Lasater KB, Aiken LH, Sloane DM, et al. Chronic Hospital nurse understaffing meets COVID-19: an observational study. BMJ Qual Saf 2021;30:639-47.

26 Gray BM, Vandergrift JL, Barnhart BJ, et al. Changes in stress and workplace shortages reported by U.S. critical care physicians treating coronavirus disease 2019 patients. Crit Care Med 2021; Publish Ahead of Print.

27 Mascha EJ, Schober P, Schefold JC, et al. Staffing with diseasebased epidemiologic indices may reduce shortage of intensive care unit staff during the COVID-19 pandemic. Anesth Analg 2020;131:24-30.

28 Gelfman DM. Will the traditional physical examination be another casualty of COVID-19? Am J Med 2021;134:299-300.

29 Shah AG, Taduran C, Friedman S, et al. Relocating IV pumps for critically ill isolated coronavirus disease 2019 patients from bedside to outside the patient room. Crit Care Explor 2020;2:e0168.

30 Fakih MG, Bufalino A, Sturm L, et al. Coronavirus disease 2019 (COVID-19) pandemic, central-line-associated bloodstream infection (CLABSI), and catheter-associated urinary tract infection (CAUTI): the urgent need to refocus on hardwiring prevention efforts. Infect Control Hosp Epidemiol 2021:1-6.

31 W-j G, Z-y N, Hu Y. Clinical characteristics of coronavirus disease 2019 in China. N Eng J Med 2020;382:1708-20.

32 Richardson S, Hirsch JS, Narasimhan M, et al. Presenting characteristics, comorbidities, and outcomes among 5700 patients hospitalized with COVID-19 in the new York city area. JAMA 2020;323:2052-9.

33 Yehia BR, Winegar A, Fogel R, et al. Association of race with mortality among patients hospitalized with coronavirus disease 2019 (COVID-19) at 92 US hospitals. JAMA Netw Open 2020;3:e2018039.

34 Bourgeault IL, Maier CB, Dieleman M, et al. The COVID-19 pandemic presents an opportunity to develop more sustainable health workforces. Hum Resour Health 2020;18:83. 